\title{
Disruption of endogenous tidal rhythms of larval release linked to food supply and heat stress in an intertidal barnacle
}

\author{
Paula Kasten, Augusto A. V. Flores* \\ Universidade de São Paulo, Centro de Biologia Marinha, Rodovia Manoel Hipólito do Rego, Km 131.5, 11600-000, \\ São Sebastião, São Paulo, Brazil
}

\begin{abstract}
The timing of larval release may greatly affect the survivorship and distribution of pelagic stages and reveal important aspects of life history tactics in marine invertebrates. Endogenous rhythms of breeding individuals and populations are valuable indicators of selected strategies because they are free of the neutral effect of stochastic environmental variation. The highshore intertidal barnacle Chthamalus bisinuatus exhibits endogenous tidal and tidal amplitude rhythms in a way that larval release would more likely occur during fortnightly neap periods at high tide. Such timing would minimize larval loss due to stranding and promote larval retention close to shore. This fully explains temporal patterns in populations facing the open sea and inhabiting eutrophic areas. However, rhythmic activity breaks down to an irregular pattern in a population within the São Sebastião Channel subjected to large variation of food supply around a mesotrophic average. Peaks of chl a concentration precede release events by 6 d, suggesting resource limitation for egg production within the channel. Also, extreme daily temperatures imposing mortality risk correlate to release rate just $1 \mathrm{~d}$ ahead, suggesting a terminal reproductive strategy. Oceanographic conditions apparently dictate whether barnacles follow a rhythmic trend of larval release supported by endogenous timing or, alternatively, respond to the stochastic variation of key environmental factors, resulting in an erratic temporal pattern.
\end{abstract}

KEY WORDS: Reproductive timing - Endogenous rhythm - Thermal stress - Phytoplankton · Chthamalus bisinuatus

\section{INTRODUCTION}

Synchronized reproduction is widely accepted as an adaptive trait that ultimately maximizes viable offspring generation. Many studies have provided evidence that finely tuned timing of breeding activities implies different physiological and behavioral traits selected to either optimize reproductive output by increasing mating or fertilization success (e.g. Korringa 1947, Caspers 1984, Harrison et al. 1984) or promote offspring release when environmental conditions are best for early survival and growth. In this latter case, reproductive activities must be controlled by variables signaling favorable situations, such as food availability or low predation risk (e.g. Himmelman 1975, Starr et al. 1990, Morgan \& Christy 1994). However, temporal reproductive patterns may also be the result of adaptive responses to persistent unfavorable conditions, leading to alternative reproductive strategies.

Cyclical natural variables are extensively used by many organisms to time reproductive activity, and anticipatory behaviors are possible after an entrainment period (Palmer 1995). Natural reproductive rhythms matching these cycles are widely reported, and there is evidence of endogenous control in many cases. Precise timing of larval release over tidal and diel cycles, for instance, may minimize predation risk 
of both mothers and larvae (see Forward 1987 and Morgan 1995 for reviews). In contrast, variation of erratic variables is far more difficult to anticipate. Adaptive responses to unexpected environmental change may consist of breaking down an eventual endogenous program and implementing an alternative pathway (Roitberg et al. 1993, Javoiš \& Tammaru 2004). Undoubtedly, many organisms often face disruptive stimuli from different sources, but their relative importance in determining temporal trends is often not assessed. Since synchronization of breeding activities is paramount to maximize reproductive output, understanding how the combined effects of endogenous components and environmental stochastic triggers affect the timing of larval release across variable natural conditions is of major importance.

Sessile marine invertebrates inhabiting the intertidal zone are exposed to harsh physical conditions, such as heat stress and desiccation when exposed to air (e.g. Lewis 1964, Newell 1970, Helmuth \& Hofmann 2001). Food supply for filter feeders can easily fall below critical levels, limiting reproduction and growth, because pelagic nearshore primary production is highly variable in space (Harris 1980, Mackas et al. 1985, Strutton et al. 1997) and time (Harris 1980, Cloern 1996), especially at lower latitudes where nutrient depletion occurs frequently (Le Bouteiller et al. 1992, Switzer et al. 2003). Under such adverse conditions, plastic reproductive traits may permit alternative responses, which do not necessarily increase chances of offspring survival but would be adaptive if mortality risk for adults is high.

The intertidal acorn barnacle Chthamalus bisinuatus predominates in the higher intertidal zone along the subtropical southeastern coast of Brazil. Settlement of this species is high below its dominance belt, but mussels Brachidontes solisianus smother barnacle recruits at this lower level (Eston et al. 1986, Tanaka \& Duarte 1998). At the upper shore, where adults predominate, populations might be subjected to both heat stress and low food supply, because nutrient concentration in tropical waters is often very low and because immersion times for these uppershore barnacles, when they feed, are too short. In natural populations within the Santos region (SR), Bueno et al. (2010) reported a very clear fortnightly rhythm of larval release in this species, but the rhythm was centered on neap-tide periods, not spring tides, as is commonly documented for other invertebrate species. We hypothesized that neap-tide larval release would promote larval retention, since tidal currents are weakest in this period, and that larval stranding risk would be the lowest, because adults would never be totally immersed and would have to use high-tide splash to release their nauplii.

This study follows the work by Bueno et al. (2010), by first examining the endogenous timing of Chthamalus bisinuatus in the laboratory without the effect of any environmental cues other than the ones we used to test entraining mechanisms. This endogenous response would indicate how barnacles will use natural cycles to time their reproductive activity in the absence of stochastic environmental stressors. We then verify whether this optimal timing is compatible with the natural trend found at SR and, therefore, whether our early interpretations on its adaptive value are valid. We then sampled a second locality $100 \mathrm{~km}$ from SR, within the São Sebastião Channel (SSC) and exposed to contrasting nearshore pelagic conditions, and advanced possible causes of departures from optimal timing by testing the association of reproductive activity with stochastic oceanographic and meteorological variables. This correlational evidence allowed us to propose alternative reproductive tactics as a response to unpredictable environmental change.

\section{MATERIALS AND METHODS}

\section{Laboratory trials testing endogenous timing}

Barnacle populations and general handling

All laboratory experiments were undertaken at the Centre for Marine Biology of the University of São Paulo (CEBIMar/USP) at São Sebastião from January 2010 to June 2011. Rock chips were removed from the upper midlittoral zone, dominated by Chthamalus bisinuatus, at nearby Pitangueiras Beach $\left(23^{\circ}\right.$ $\left.49^{\prime} 57^{\prime \prime} \mathrm{S}, 45^{\circ} 31^{\prime} 17^{\prime \prime} \mathrm{W}\right)$ and Calhetas Beach $\left(23^{\circ} 49^{\prime}\right.$ $28^{\prime \prime} \mathrm{S}, 45^{\circ} 25^{\prime} 11^{\prime \prime} \mathrm{W}$ ), which supplied experimental barnacle populations. Although we did not attempt to compare hatching rates across trials, care was taken to use similarly sized laboratory populations to provide comparable signals in the time series of larval release. For that, rock chips were added to each aquarium to equal approximately $200 \mathrm{~cm}^{2}$ of rock surface. Patches with high barnacle cover (80 to $100 \%$ ) were selected, and total estimated population sizes were around 600 to 800 large adult individuals, with a small size variation because there was almost no clear space for new recruits on these rock chips.

These populations were maintained indoors at $25^{\circ} \mathrm{C}$ in separate square glass aquaria $(30 \times 30 \times$ 
$20 \mathrm{~cm}$ ) and held underwater in running filtered seawater $(3 \mu \mathrm{m})$, except for experiments testing the effect of immersion. Fluorescent lamps (500 lux) were used when a light phase was required. A central outflow pipe drained off excess water. General handling was the same in all trials. During the acclimation period, when barnacles were exposed to artificial variation of environmental cues, water was filtered every day at the same time through a $100 \mu \mathrm{m}$ plankton mesh to monitor daily naupliar release. After sampling, the animals were fed ad libitum for half an hour, always at the same time, using natural live plankton concentrates filtered at nearshore spots within the CEBIMar area.

Entrainment of tested variables was held until a hatching event was detected (5 to $46 \mathrm{~d}$ ). During the following $5 \mathrm{~d}$, barnacles were held in constant conditions $\left(25^{\circ} \mathrm{C}\right.$ and constant darkness, except for the second trial of photoperiod manipulation), and sampling was conducted hourly for experiments testing the endogenous control of ultradian activities, i.e. those with a frequency higher than the day-night cycle. Constant dark was preferred because natural reproductive cycles may be altered in constant light, as shown for other barnacle species (Crisp \& Patel 1969). There were no attempts to deliver tidal amplitude (ca. $14 \mathrm{~d}$ ) or other low-frequency cycles in the lab. In this case, we relied on the entrainment of natural rhythms in the field, prior to captivity, and examined temporal patterns in a free-running barnacle population, i.e. held indoors without external stimuli and in constant conditions for $60 \mathrm{~d}$. Larvae were counted daily throughout this period. When numbers were exceedingly high, a Folsom plankton splitter was used to obtain subsamples of countable size. All larvae were preserved in $70 \%$ alcohol.

Entrainment by single environmental variables

In the following set of experiments, barnacle populations were held in similar constant conditions but were subjected to a regular variation of key variables, one in each experiment, to identify single entraining factors mediating a rhythmic endogenous response of larval release. Artificial cycles did not match those taking place in nature. A different barnacle population was used in each experiment.

Circadian rhythm (light). A timer was used to set an ambient dark-light cycle of $12 \mathrm{~h}: 12 \mathrm{~h}$, inverse to natural conditions, ensuring that eventual proceeding of rhythmicity was related to this artificial regime and not entrained while animals were still in the field.
Two different populations were held in the laboratory for $5 \mathrm{~d}$ under these settings and then maintained in constant free-running conditions. One of these populations was kept in constant darkness, and the other was kept in constant light.

Circadian rhythm (temperature). During the entrainment period, room air conditioning and a thermostat coupled with a timer were used to generate a temperature cycle of $14 \mathrm{~h}$ at $21^{\circ} \mathrm{C}$ and $10 \mathrm{~h}$ at $27^{\circ} \mathrm{C}$ in a 501 reserve water tank that supplied water to the experimental population. These temperature settings were chosen to simulate a natural austral winter regime, which is when this trial was conducted. After $10 \mathrm{~d}$, a release peak was detected, and hourly observations at constant conditions began. Both light and temperature variation would entrain a $24 \mathrm{~h}$ cycle of larval release.

Circatidal rhythm (immersion). Tidal cycles were simulated in the laboratory $46 \mathrm{~d}$ prior to a release event. During this period, the experimental aquarium was filled with seawater for 30 min every $12.4 \mathrm{~h}$ using an external electric pump attached to a $50 \mathrm{l}$ reserve water tank. This is the expected immersion regime in the upper midlittoral zone at the transition from spring to neap tides in this region. When switched on, a timer ensured water supply to barnacles during an artificial flood tide. When switched off, the water drained off by gravity, thus simulating an ebbing tide. For this experiment, barnacles were maintained in a 121 plastic bucket to which a lateral thin rubber hose (5 $\mathrm{mm}$ diameter) was attached, allowing slow drainage. The free-running period started after $46 \mathrm{~d}$, when a release event was detected.

Circatidal amplitude rhythm without artificial entrainment. In this case, a barnacle population was kept in free-running conditions for $60 \mathrm{~d}$, without prior laboratory manipulations. Larvae were counted daily. If an endogenous clock contributes to the tidal amplitude rhythm observed by Bueno et al. (2010), then a periodicity of around $14 \mathrm{~d}$, equivalent to the springneap cycle, was expected to be found in the larval release activity of these captive barnacles.

\section{Entrainment by a combined effect of environmental variables}

In a more complex mechanism, a zeitgeber, i.e. the synchronizing variable, would only be allowed to operate given that a second oscillator is present. To test whether more than 1 variable is needed to trigger an endogenous response, 2 combinations of 2 
environmental factors were tested. The procedures were the same as explained for the single-variable cases. First, the combined effect of immersion and light was tested by superimposing inundation at every $12.4 \mathrm{~h}$ and $12 \mathrm{~h}$ light: $12 \mathrm{~h}$ dark cycle. Free-running conditions started after $27 \mathrm{~d}$ when a release event was detected. Second, the combination of immersion and temperature was tested using the same artificial tide regime coupled with a cyclic variation of temperature $\left(10 \mathrm{~h}\right.$ at $27^{\circ} \mathrm{C}$ and $14 \mathrm{~h}$ at $\left.21^{\circ} \mathrm{C}\right)$ for $10 \mathrm{~d}$ until hatching resumed. We did not test the combined effect of temperature and photoperiod because both could potentially lead to a circadian rhythm, and thus it would not be possible to discern which one was the responsible driver. As above, exposure to artificial environmental variation in these 2 trials was followed by a free-running period of $5 \mathrm{~d}$, when conditions were held constant. During this period, the number of nauplii was recorded hourly.

\section{Rhythms and response to stochastic drivers in the field}

\section{Study localities}

Sampling was conducted along the central coast of São Paulo State, Brazil (Fig. 1). This region is subjected to a microtidal regime, with spring-tide amplitude ranging between 1.1 and $1.5 \mathrm{~m}$. Hence, wind stress may add significant variation to sea level oscillation depending on coastal topography (Middleton
1991, Bernier \& Thompson 2007) and thus potentially hamper the entrainment of tidal cycles of activity in Chthamalus. We compared results obtained by Bueno et al. (2010) within SR (Fig. 1), where shores face the open ocean and are exposed to eutrophic conditions from urban pollution (Braga et al. 2000), to results obtained in this study at the SSC. Within the SSC, wind stress accounts for an average surface sea level variation of $20 \%$ from what is predicted by tidal charts, occasionally exceeding $50 \%$ after persistent longshore forcing (A.A.V. Flores unpubl. data), eventually blurring tidal signaling. Also, there are no signs of eutrophication in this region, and waters remain oligotrophic during summer most of the time, when the influence of the warm, nutrient-poor Brazilian Current is strongest (Aidar et al. 1993).

\section{Long-term time series}

To verify whether the clear fortnightly pattern observed at replicate sites within SR (Bueno et al. 2010) is a more general trend, we obtained a daily time series of naupliar release at Baleeiro Head $\left(23^{\circ} 49^{\prime} 45^{\prime \prime} \mathrm{S}, 45^{\circ} 25^{\prime} 25^{\prime \prime} \mathrm{W}\right)$, located in the SSC and enclosed in the CEBIMar area. Naupliar release was estimated by using a specific trap designed to measure propagule release in sessile marine invertebrates (Bueno \& Flores 2008). Six sites at vertical walls with dense barnacle cover, separated by some tens of meters, were selected and sampled daily according to the protocol described by Bueno et al. (2010). Briefly, each of these sites encompassed 10 neighbor-

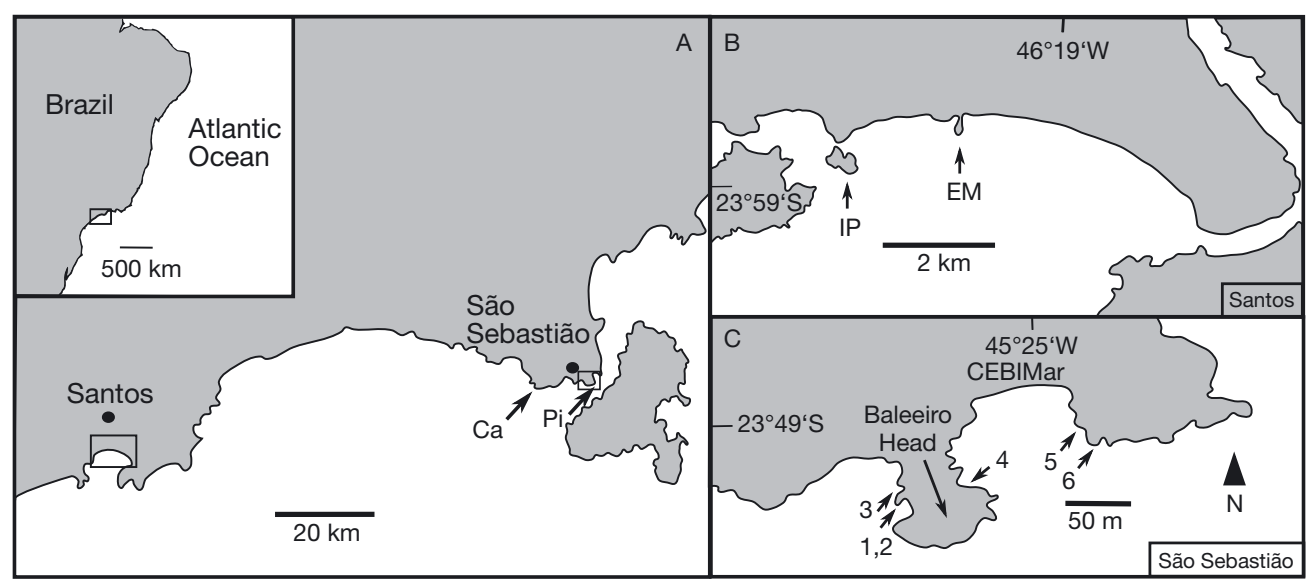

Fig. 1. Study locations and sampling sites. (A) Central coast of São Paulo State, showing the 2 main localities sampled in this study; the Santos Region (SR) and the São Sebastião Channel (SSC), and the position of Calhetas (Ca) and Pitangueiras (Pi), from which barnacles were obtained for laboratory experiments. (B) Study sites in SR (IP: Ilha Porchat; EM: Emissário).

(C) Study sites in SSC (1 to 6) within the CEBIMar area 
ing trap positions $(9 \times 9 \mathrm{~cm}$ each), randomly sampled by a single trap without repetition over blocks of 10 d. Daily, trap contents were sieved and stored in $70 \%$ ethanol. Sampling at Baleeiro Head started on December 30, 2008, and ended on April 17, 2009, thus covering a period exceeding $100 \mathrm{~d}$, which is long enough to test for fortnightly rhythmicity.

\section{Short-term time series}

Because the previous long-term time series at Baleeiro Head differed substantially from what was observed at Santos and from what could be expected by endogenous control (see 'Results'), a shorter daily time series of larval release was obtained at the same area from January 29 to March 1, 2011, thus encompassing a $32 \mathrm{~d}$ period. In this case, responses to stochastic environmental drivers were the focus instead. We sampled a set of sites within Baleeiro and the neighboring coastline for both naupliar release and environmental variables and used daily average values in the time series. Since sites within Baleeiro differed in their exposure to important variables, we also tested for contrasts of reproductive timing and output according to levels of variation of these factors and, hence, for variability within this relatively small spatial scale.

Six sites around CEBIMar, scattered along a rocky coastline of $350 \mathrm{~m}$, separated by distances ranging from 2 to $80 \mathrm{~m}$ (Fig. 1), and lying in vertical walls with different orientation, were delimited for sampling. Monitoring larval release followed the above protocol exactly except that 2 traps, not 1 , were operated simultaneously at each site to increase precision. Potential environmental variables capable of overriding eventual endogenous reproductive rhythms include chl a concentration (as a proxy of phytoplankton standing stock and, thus, food supply), temperature, and water flow, which were monitored daily at all sampling sites (only one chl a dataset was recorded for Sites 1 and 2, because they were just $2 \mathrm{~m}$ apart and shared a common nutrient flow).

For chl a quantification, daily filtration of two $500 \mathrm{ml}$ replicate samples of surface seawater at each sampling site was undertaken using a vacuum filtration kit and Whatman ${ }^{\circledR}$ GF/F 25 um glass microfiber filters. Filters were then placed in light-protected vials containing $5 \mathrm{ml}$ of a precooled mixture of $90 \%$ acetone and dimethyl sulfate oxide $(6: 4$ in volume; Shoaf \& Lium 1976) and were stored for at least $24 \mathrm{~h}$ in a freezer. After this period, samples were taken to room temperature, again protected from light, and the extraction fluorescence was quantified on a AquaFluor ${ }^{\mathrm{TM}}$ handheld fluorometer (Turner Designs, Sunnyvale, CA), following US Environmental Protection Agency Method 445 (Arar \& Collins 1997).

To assess heat stress at each site, iButton ${ }^{\circledR}$ data loggers were mounted to $5 \times 5 \mathrm{~cm}$ PVC plates attached to the rock surface, and their outer surfaces were covered with a very thin transparent silicon layer, which did not alter temperature readings but which retarded deterioration of the loggers. Temperature records were obtained at 10 min intervals.

Water flow over each site was estimated based on the mean weight loss of 2 plaster cylinders attached close to the barnacle population. Cylinders were $6 \mathrm{~cm}$ long, $4 \mathrm{~cm}$ wide, and coated with a maritime varnish layer (except the top surface) so that they were dissolved from the top to the bottom but not through the sides, thus providing a nearly linear response to water flow. Because food supply may be limited by not only phytoplankton standing stock but also water flow over the barnacles, chl a supply was estimated by multiplying water flow by chl a concentration. Average daily wave heights were obtained using the Global Forecast System model, run 8 times a day, for SSC. These data are available at www. windguru.cz/pt/.

\section{Numerical and statistical analyses}

Time series analyses

All data series obtained from the laboratory experiments, as well as the field long-term time series of naupliar release, were subjected to spectral analysis combined with autocorrelation techniques to verify the existence of periodic components. Significant periodicity was verified by plotting first a periodogram to inspect major peaks within expected frequencies (Rayner 1971) and then the distribution of observed periodogram values in size classes and their expected frequencies for a negative exponential distribution, which characterize a random series. Differences between observed and expected values were tested using Kolmogorov-Smirnov (K-S) 1sample tests (Sokal \& Rohlf 1995). If contrasts were significant, then the data were subjected to autocorrelation analyses at lags $\pm 1 / 4$ the total series length (Chatfield 1989) to verify whether major periodogram peaks are supported by significant correlation at the respective lags.

Cross-correlations between release rates and monitored environmental variables in the field were car- 
ried out following the recommendations of Pyper \& Peterman (1998). Instead of fitting autoregressive models to data and correlating residual series, we corrected degrees of freedom $\left(N^{*}\right)$ using Eq. (1):

$$
\frac{1}{N^{*}}=\frac{1}{N}+\frac{2}{N} \sum_{j=1}^{\infty} \frac{(N-j)}{N} \rho_{X X}(j) \rho_{Y Y}(j)
$$

where $N$ is sample size, and $\rho_{X X}$ and $\rho_{Y Y}$ are autocorrelations of $X$ and $Y$ at lag $j$. After computing corrected degrees of freedom, the significance levels of correlations were recalculated. Autocorrelation coefficients were also corrected according to Chatfield (1989) using Eq. (2):

$$
\rho_{X X}(j)=\frac{N}{N-j} \times \frac{\sum_{t=1}^{N-j}\left(X_{t}-\bar{X}\right) \times\left(X_{t+j}-\bar{X}\right)}{\sum_{t=1}^{N}\left(X_{t}-\bar{X}\right)^{2}}
$$

Analyses of variance of field data

Sampling sites used in the short-term time series were classified as either 'hot' vs. 'cool' or 'nutrientrich' vs. 'nutrient-poor' by plotting and comparing cumulative frequency distributions of temperature and chl a data obtained at each site. We selected the most different sites, according to either 'temperature' or 'food supply', to include temporal replication within each level ( $\mathrm{n}=2$ sites; Table 1$)$ of those fixed factors. 'Site' was then considered a random factor, nested in either 'temperature' or 'food supply', and replication within sites differed whether the response variable was the timing of larval release or larval release rate.

Table 1. Small-scale environmental variability at Baleeiro Head and adjacent rocky coastline within the São Sebastião Channel, São Paulo. Levels within environmental factors were discriminated by inspection of cumulative frequency distributions of temperature and chl a concentration (a proxy for food supply) at each sampling site (see Fig. 1). Extreme records, not median values, were the most informative to distinguish environmental conditions, namely percentiles 90 for temperature (38 to 39 and 30 to $31^{\circ} \mathrm{C}$ for hot and cool sites, respectively) and 85 for food supply (2.0 to 2.8 and 0.9

to $1.2 \mu \mathrm{g} \mathrm{chl} \mathrm{a} \mathrm{l}^{-1}$ for rich and poor sites, respectively)

\begin{tabular}{|lcc|}
\hline Environmental factor & Factor level & Site \\
\hline Temperature & Hot & 1,3 \\
& Cool & 2,4 \\
Food supply & Nutrient-rich & 4,5 \\
& Nutrient-poor & $1-2,3$ \\
\hline
\end{tabular}

The timing of larval release was examined based on the relative number of larvae released during hatching events, which were observed roughly at the same time $( \pm 1 \mathrm{~d})$ in all sites. Because average release differed among sites, hatching magnitude (larval release at peak date minus baseline activity, i.e. $1 \mathrm{~d}$ and $6 \mathrm{~d}$ before in the case of temperature and chl $a_{\text {, }}$ respectively, as indicated in 'Results') was divided by mean release rate at each site. Data were obtained for 6 distinct hatching events at each site.

Larval release rate, corrected for population density, was also compared across environmental conditions. Because larval release is a measure of fecundity (thus, linearly related to weight and hence volume; e.g. Hines 1978, Burrows et al. 1992) and barnacle density is an estimate per unit area, corrected values were obtained by dividing larval counts by the $3 / 2$ power of percent substrate cover. Estimates of barnacle population density were obtained by placing gridded quadrats, with regular intersections at $5-\mathrm{cm}$ intervals, against the rock face, and counting the number of intersections lying over live barnacles. An average of 100 points was needed to scrutinize the whole area, but variation was substantial (from 60 to 180); areas were of different sizes because of variable spacing between trap positions to avoid irregular surfaces when installing the traps. Average error margins were $23 \%$, at $95 \%$ statistical confidence, around average values, and precision was not correlated to percent cover $(\mathrm{r}=-0.109 ; F=$ $1.59, \mathrm{p}=0.27)$. In this case, all larval release records were used $(n=32)$, since data were not temporally autocorrelated for any given site.

Separate analyses were carried out for sites arranged according to temperature and nutrient contrasting conditions and to test for larval release timing and larval release rate. For all cases, data were square root transformed to achieve homoscedasticity. For the analysis testing the effect of food supply on larval release rate, variances remained heterogeneous even after transformation (Cochran's $C<0.05$ ). However, because this is a balanced design and the sample size is large $(n=32)$, the outcomes of the analysis should not be critically affected (Underwood 1997).

\section{RESULTS}

\section{Endogenous control}

Distribution of periodogram values differed significantly from the exponential function expected for a random set of data for all time series of naupliar 


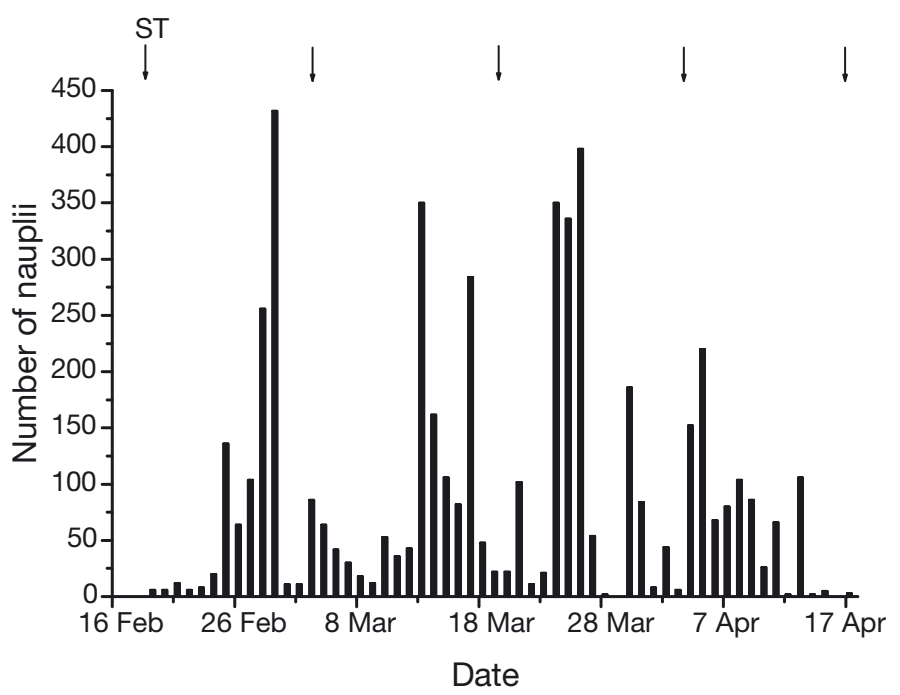

Fig. 2. Free-running time series of larval release (60 d) in constant laboratory conditions. Arrows indicate the dates of maximum ampltude spring tides (ST)

release obtained after artificial exposure of cycles of both single or combined variables $(0.3123<\mathrm{K}-\mathrm{S} d<$ $0.5491 ; \mathrm{p}<0.05$ in all cases), except for the trial in which barnacles were subjected to a tidal simulation alone $(d=0.1594 ; \mathrm{p}>0.05)$. However, significant periodicity was only supported by autocorrelation analyses in the 2 cases below.

\section{Tidal amplitude cycles}

Persistent free-running rhythmicity was observed for the barnacle population maintained over a longer period and examined for cyclic behavior at lower frequencies. In this case, release maxima mostly coincided with neap periods taking place in the field at the beginning of the series (Fig. 2) but approximated to the spring phase later on, because this endogenous cycle, with a period of 12 to $13 \mathrm{~d}$ (Fig. 3), was somewhat shorter than the tidal amplitude cycle $(14.7 \mathrm{~d})$. This behavior would help maintain the spring-neap cycle observed in SR by Bueno et al. (2010, replotted in Fig. 4A), with maxima in the neap phase, but may not warrant fortnightly cycles in other areas, such as SSC (Fig. 4B). In this latter case, temporal larval release departed from a stochastic pattern $(d=$ $0.2365 ; \mathrm{p}<0.05)$, mostly due to harmonic components at very high frequency (periods 1 to $7 \mathrm{~d}$ ) and without any peaks at lower frequency boundaries, which could be related to the tidal amplitude cycle. It is also noteworthy that release rates are around an order of magnitude higher in Santos (Fig. 4).
Tidal cycles

The second case resulting in a clear endogenous response corresponds to the experiment in which barnacles were provided an artificial diel oscillation of temperature coupled with a tidal cycle. After an entraining period of $10 \mathrm{~d}, 5$ release pulses, with decreasing magnitude through time, were very apparent (Fig. 5). Again, events of larval release started coinciding with what would be 'high tides' if artificial tides were maintained, but intervals between hatching events became shorter later on in the series. In this case, periodogram values and autocorrelation analysis indicate a significant period at $12 \mathrm{~h}$ (Fig. 6), slightly shorter than the tidal cycle.

\section{Factors affecting larval release in the field}

Temporal trends

A shorter period of naupliar release, obtained in 2011, and all monitored variables are shown in Fig. 7.
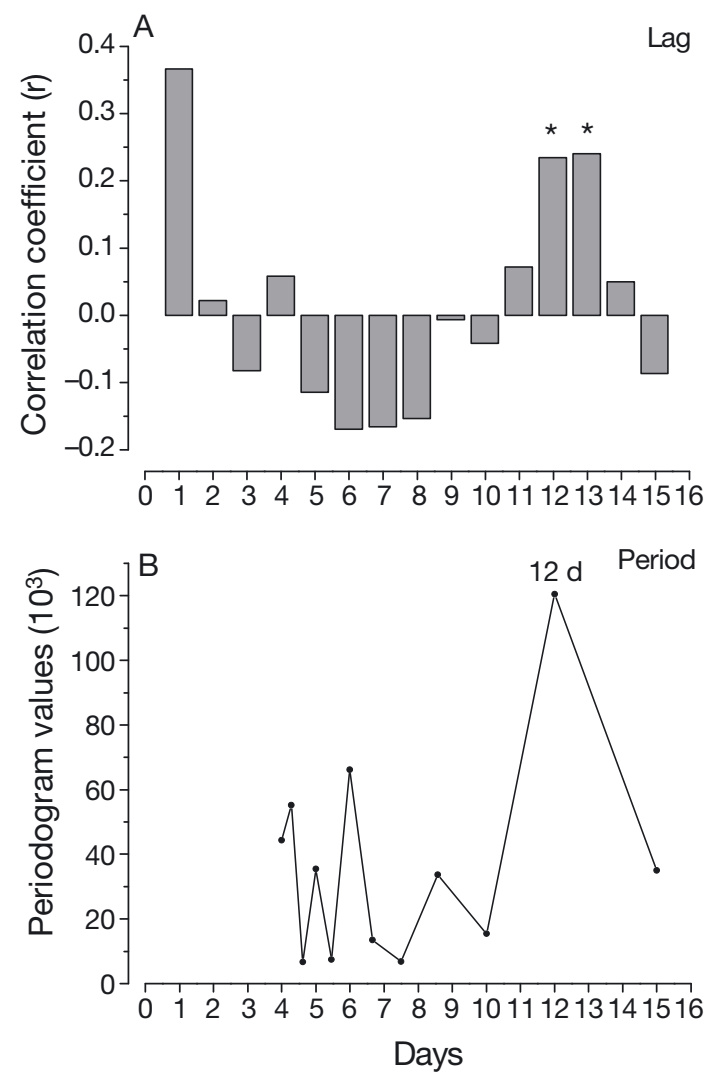

Fig. 3. (A) Autocorrelation and (B) periodogram of the $60 \mathrm{~d}$ daily naupliar release time series testing the significance of endogenous circatidal amplitude rhythms. ${ }^{*} \mathrm{p}<0.05$ 


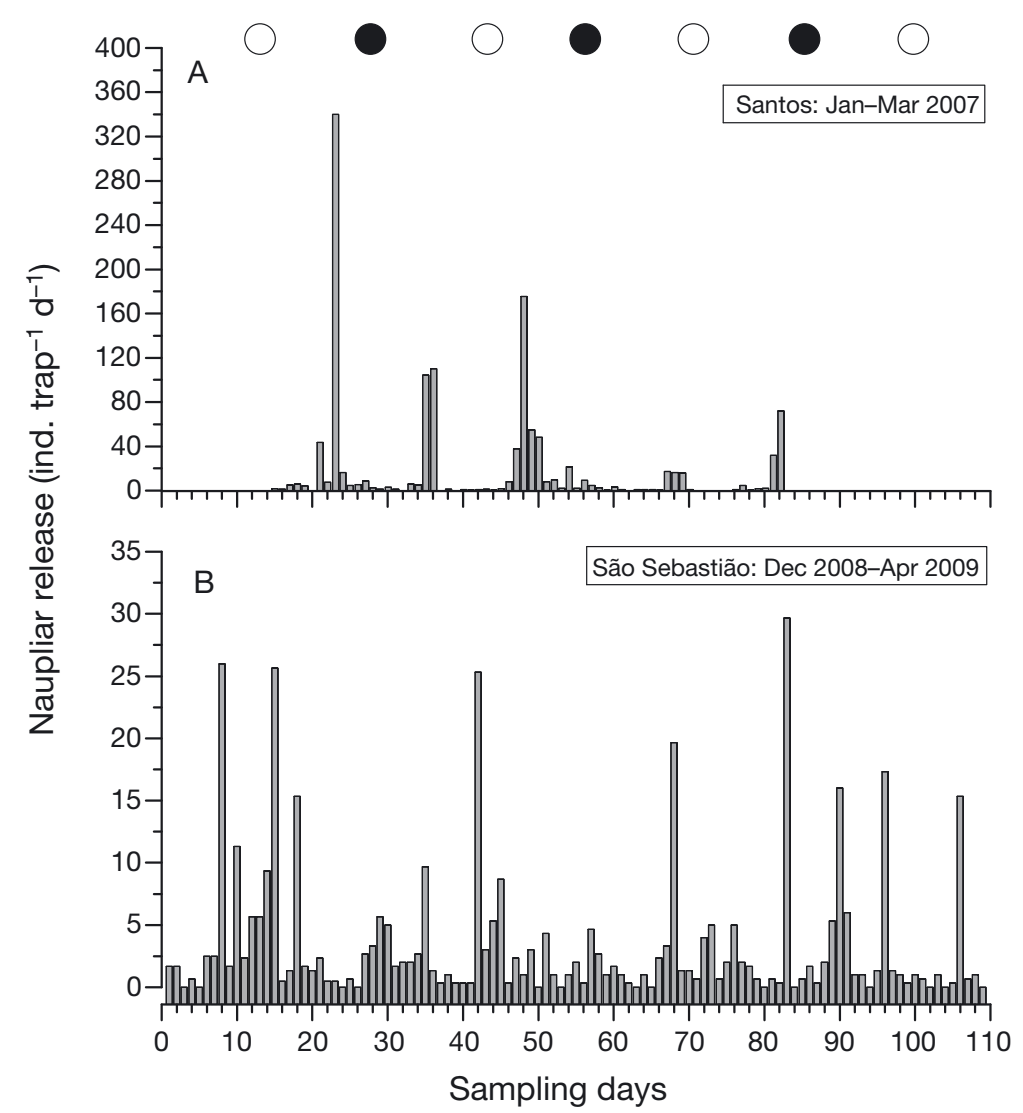

Fig. 4. Field monitoring of larval release in contrasting environmental conditions. (A) Rhythmic release of nauplii in populations of Chthamalus bisinuatus within the eutrophic Santos region, facing the open ocean (January-March 2007, adapted from Bueno et al. 2010), and (B) irregular temporal pattern in the southern São Sebastião Channel (December 2008-April 2009). The dates of full and new moons are represented as white and black circles above the series
Average temperature at the rock surface was $28.8^{\circ} \mathrm{C}$, and peak daily values (percentile 97.5) varied around a mean of $34.1^{\circ} \mathrm{C}$, exceeding $40.0^{\circ} \mathrm{C}$ on one date. Average values are fairly good predictors of extreme temperatures, but the latter was more variable (variation coefficients of average and percentile 97.5 records were 4.6 and $10.0 \%$, respectively), as observed during the period from February 2 to 16. Short, very hot events of a few hours may result from a specific combination of tide level (low), wind (low), and direct sunlight on sunny days, adding substantial variation to the series. The 6 most important extreme temperature peaks roughly coincided with the 6 most important release events (Fig. 7). Crosscorrelation analyses indicated a single significant, and positive, relationship at $-1 \mathrm{~d}$ (Table 2), suggesting that barnacles respond rapidly to excessively high temperature by releasing their larvae the following day.

Flow over the rocks, estimated from the weight loss of plaster cylinders, varied in an irregular pattern, indicating that the tidal amplitude cycle does not dictate flow regime over these barnacles. Putting aside wind-driven sea level anomalies, immersion for continuous periods are possible only during spring tides, which took place around February 3 and 18 (Fig. 7). Yet, peak flow values were observed at the first

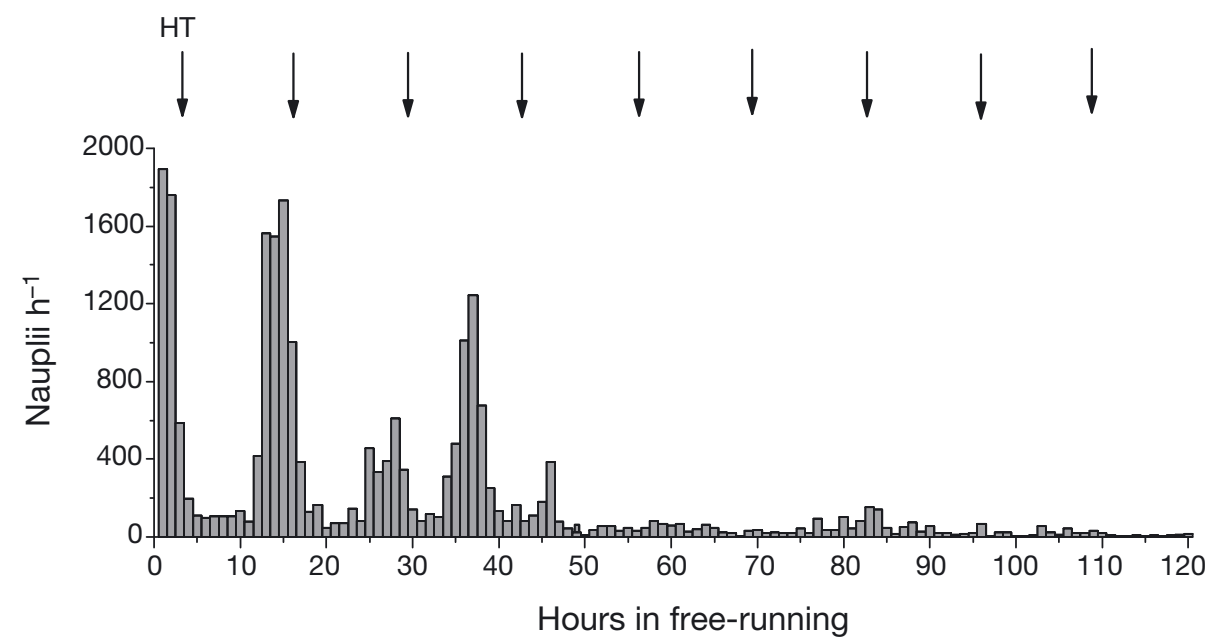

Fig. 5. Circatidal larval release in constant free-running conditions after exposure to temperature cycles $\left(10 \mathrm{~h}: 14 \mathrm{~h} ; 27^{\circ} \mathrm{C}: 21^{\circ} \mathrm{C}\right)$ and periodic 30 min immersion simulating natural tides (12.4 h inundation intervals) during an entraining period of $10 \mathrm{~d}$. Top arrows indicate the schedule of high tides (HT) 

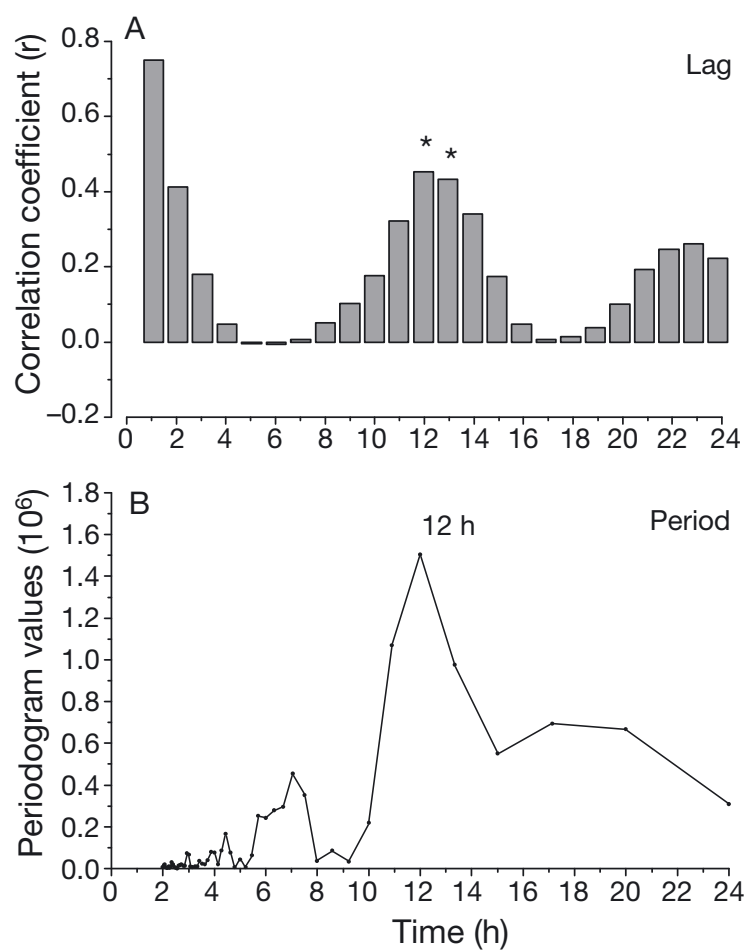

Fig. 6. (A) Autocorrelation and (B) periodogram of the $5 \mathrm{~d}$ hourly naupliar release time series testing the significance of circatidal rhythms. ${ }^{*} \mathrm{p}<0.05$

Table 2. Results of cross-correlation analyses between larval release and the environmental variables monitored. ns: not significant

\begin{tabular}{|c|c|c|c|}
\hline \multirow[t]{2}{*}{ Variable } & \multicolumn{3}{|c|}{ Larval release } \\
\hline & $\operatorname{Lag}(d)$ & $\mathrm{r}$ & $\mathrm{p}$ \\
\hline Mean temperature & - & - & ns \\
\hline $\begin{array}{l}\text { Extreme temperature } \\
\text { (percentile 97.5) }\end{array}$ & 1 & +0.424 & 0.018 \\
\hline Chl a & 6 & +0.481 & 0.005 \\
\hline Chl a flow & - & - & ns \\
\hline
\end{tabular}

transition from neap to spring tides and at the lowest amplitude tidal range in the last neap period. Flow was also uncorrelated to wave height (maximum $\mathrm{r}=$ $0.34, p>0.05,2 \mathrm{~d}$ ahead). These results indicate that flow rate at the high midshore in this area is a complex and largely unpredictable combination of tidal immersion and wave action.

Average chl a concentration varied around a mean value of $1.15 \mu \mathrm{g} \mathrm{l} \mathrm{l}^{-1}$, which would indicate prevailing mesotrophic conditions (Lalli \& Parsons 1997, Weinbauer et al. 1993). Yet, this average value is influenced by scattered events of high productivity, raising a baseline median value of $0.97 \mathrm{\mu g} \mathrm{l}^{-1}$ to eutrophic conditions during short periods (1 to 2 d), except for the last 5 days when high productivity was sustained for a longer period. These short bursts are apparently linked to release events spread over the first $3 / 4$ of the time series length. In this case, however, the response of barnacles lagged by $6 \mathrm{~d}$ (Table 2). There was no gain after correction for flow. In fact, chl a flow was not correlated to naupliar release at any tested lag.

\section{Small-scale spatial trends}

Summary statistical results on small-scale differences in the timing and rate of larval release, according to temperature and nearshore food supply, are shown in Table 3 . The relative magnitude of peak events, as a proxy of release timing, did not differ between contrasting conditions of thermal stress or chl a concentration found at the coastline along Baleeiro Head. There were also no differences between sites within each of the 2 conditions of temperature and chl a concentration. Therefore, spatial differences of temperature and food supply at the sampled scale (i.e. up to a few hundred meters) apparently do not interfere with the capacity of these barnacles to synchronize reproductive larval release.

Before comparing release rates of barnacle populations in these different environmental conditions, corrections for population cover were needed because barnacle cover variation was substantial (from 32 to $56 \%$ ). Release rates did not differ between conditions of thermal stress or phytoplankton supply, but there was contrasting reproductive output between sites within these environmental conditions. Thus, small-scale variability of reproductive output does occur within populations of this barnacle species, but they are apparently not associated with heat stress or phytoplankton concentration.

\section{DISCUSSION}

\section{Endogenous control and its adaptive significance}

Endogenous rhythms in Chthamalus bisinuatus provide further support for the retention-favorable strategy proposed by Bueno et al. (2010), based on field data. We show in this study that adults naturally tend to release most of their nauplii at high tide during neap periods, when tidal immersion is unlikely and breeding barnacles have to respond rapidly to wave splash. The adaptive value of these tide-related 

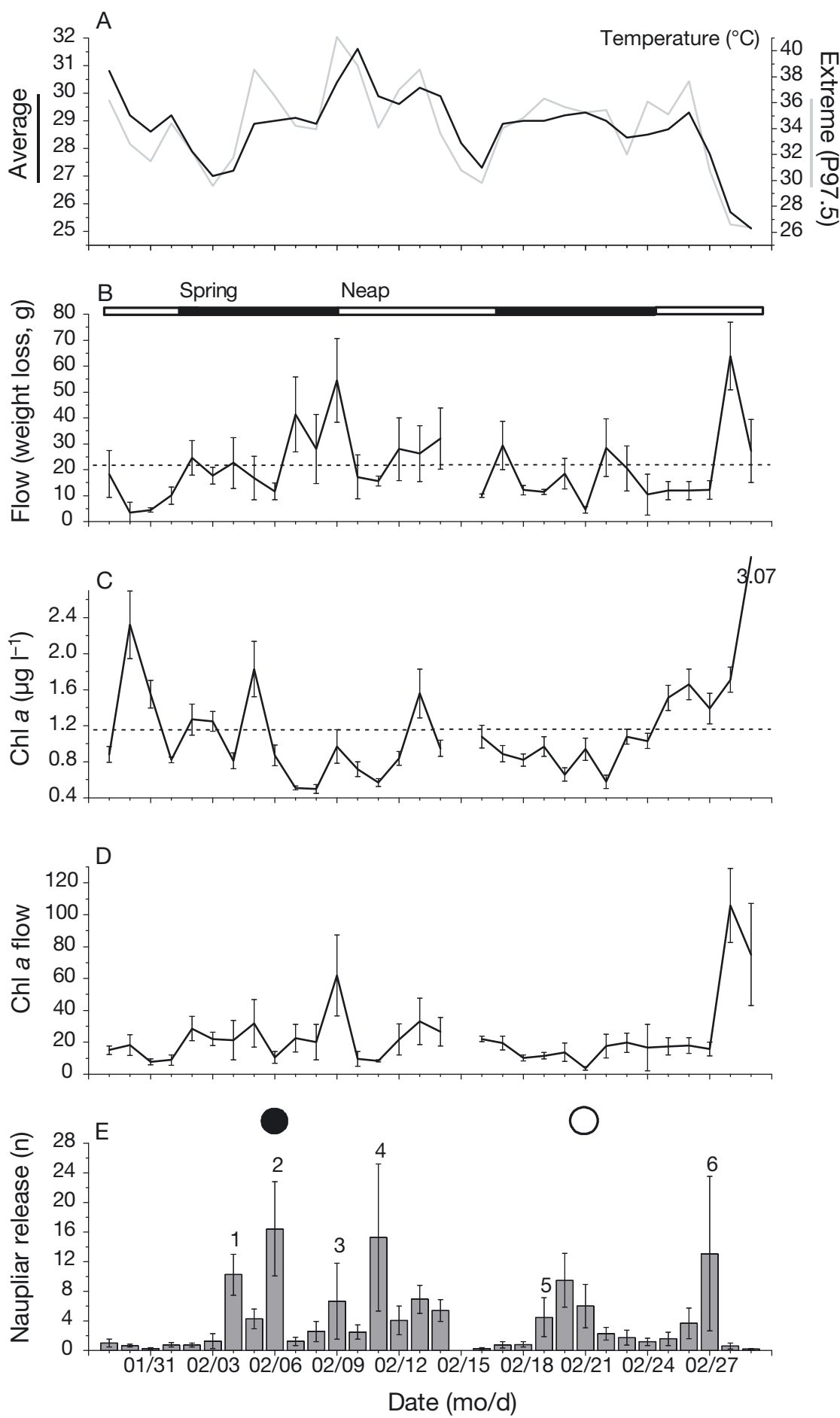

rhythms is that larval survival would be enhanced by minimizing both stranding risk, because there is no further tidal or wave runup to higher levels at release time, and excessive offshore transport, because tidal currents during neap periods are the weakest.

As far as we are aware, this is the first study testing endogenous control of reproductive activity rhythms in barnacles. An important result is the absence of a circadian rhythm, which could have been entrained by light or temperature cycles, agreeing with the lack of significant differences between natural diurnal and nocturnal release rates in the field (Bueno et al. 2010). Free-running day-night cycles are common in other marine intertidal arthropods, such as crabs (e.g. Williams et al. 1985, Chatterton \& Williams 1994), isopods (e.g. Deruyck et al. 1991, Yannicelli et al. 2001), and insects (e.g. Evans 1976, Neumann 1989), which bear complex compound eyes. In barnacles, however, ocelli are far less complex (Walley 1969), and exposure to light is limited to very brief periods when the operculum is open. These 2 facts explain why entrainment by light may be difficult in Chthamalus bisinuatus. Temperature changes associated with the daily cycle could have been used to entrain a circadian rhythm, but results indicate that this does not hold for C. bisinuatus. Apparently, this barnacle species does not take advantage of nocturnal hatching to reduce larval predation by visual consumers, as is widely accepted for other marine invertebrates (Morgan 1995).

Fig. 7. Short daily time series (32 d) of environmental variables (A) average temperature and extreme values, as percentiles 97.5 (P97.5) at the rock surface near barnacle populations, (B) flow, (C) chl a concentration, (D) chl a flow, and (E) daily larval release in the São Sebastião Channel. Average values, $\pm 1 \mathrm{SE}$, include data obtained at 6 different sites separated by 2 to $80 \mathrm{~m}$, except for temperature, due to sensor failure at Site 2, and chl a concentration and flow, for which Sites 1 and 2 were pooled because of proximity (see 'Materials and methods'). Except for temperature, there were no records on February 15 due to adverse weather conditions. Dotted horizontal lines in flow and chl a time series indicate average values. Horizontal black and white bars in (B) represent periods of spring and neap tides, respectively. In (E) numbers above bars stand for release events $(\mathrm{n}=6)$ used in the analyses comparing larval release timing, according to small-scale variation of temperature and food supply. 
Table 3. Summary results of the ANOVA model used to test for small-scale differences in the timing and rate of larval release, according to contrasting conditions of temperature and food supply at Baleeiro, São Sebastião Channel. Statistical significance is highlighted in bold

\begin{tabular}{|c|c|c|c|c|c|c|c|c|}
\hline \multirow[t]{2}{*}{ Source of variation } & \multicolumn{4}{|c|}{ Timing } & \multicolumn{4}{|c|}{ Release rate } \\
\hline & df & MS & $F$ & $\mathrm{p}$ & $\mathrm{df}$ & MS & $F$ & $\mathrm{p}$ \\
\hline Temperature & 1 & 0.06 & 0.09 & 0.79 & 1 & 68.3 & 2.12 & 0.28 \\
\hline Site (Temperature) & 2 & 0.69 & 1.35 & 0.28 & 2 & 32.0 & 3.94 & 0.02 \\
\hline Residual & & 0.51 & & & 124 & & & \\
\hline Cochran's & \multicolumn{4}{|c|}{$C=0.5150 ; \mathrm{p}>0.05$} & \multicolumn{4}{|c|}{$C=0.3552 ; \mathrm{p}>0.05$} \\
\hline Food supply & 1 & 0.01 & 0.20 & 0.70 & 1 & 19.50 & 0.27 & 0.65 \\
\hline Site (Food supply) & 2 & 0.07 & 0.10 & 0.91 & 2 & 72.86 & 7.48 & $<0.01$ \\
\hline Residual & & 0.66 & & & 124 & & & \\
\hline Cochran's & \multicolumn{4}{|c|}{$C=0.4039 ; \mathrm{p}>0.05$} & \multicolumn{4}{|c|}{$C=0.4610 ; \mathrm{p}<0.01$} \\
\hline
\end{tabular}

On the contrary, tide-related cycles were very clear, but mechanisms underlying their entrainment in the field are still unclear. Little can be advanced at this stage on the control of tidal amplitude hatching, because we monitored free-running activity without previously submitting barnacles to artificial cycles of test parameters. As discussed above, entrainment by weak-light cycles reproducing natural moonlight as observed in polychaetes (Franke 1986) and crabs (Saigusa 1980) is very unlikely. Cycles of hydrostatic pressure would also hardly entrain fortnightly rhythms, since the water column over these barnacles would never be more than a few 10s of centimeters. Vibration and sound were particularly effective in sustaining a semilunar pupation rhythm in an intertidal midge (Neumann 1978) and could eventually entrain release activity in barnacles, since mantle sensory structures extend to setae, which reach the external environment between the opercular valves (Foster \& Nott 1969). These sense organs may detect turbulence even when the operculum is closed, making possible the anticipation of water flow when all basic activities should take place.

Unlike cirral activity in other barnacle species (Southward \& Crisp 1965), sharp circatidal larval release rhythms were observed in Chthamalus bisinuatus but only after delivering a combination of immersion and temperature cycles. The synergistic effects of entraining factors were already reported to control endogenous locomotory tidal activity in the shore crab Carcinus maenas when temperature cycles are delivered in phase with immersion (Williams \& Naylor 1969) or salinity (Bolt et al. 1989) cycles. However, in our study, system temperature and immersion had different periods. Because free-running activity followed a circatidal cycle, and not a circadian one, the temperature variation played an indirect role. It is possible that temperature modulation is required for timely synthesis of the egg-hatching pheromone (Karlson \& Luscher 1959), which is released into the mantle cavity and promptly mediates release (Clare 1997), but this still needs to be tested.

\section{Temporal hatching patterns and pelagic nearshore conditions}

Unlike the temporal trend observed in $\mathrm{SR}$, the patterns recorded at SSC demonstrate that entrainment by tidal cycles can be easily disrupted by different environmental variables, removing any trace of such rhythmic behavior. Within the sampled coastline of the SSC, there was no small-scale variation in release timing or reproductive output across conditions of thermal stress or chl a concentration, suggesting that oceanographic conditions, varying between areas several 10s of kilometers apart, determine whether barnacle populations will undertake rhythmic release activity or alternatively respond to stochastic inducing factors, resulting in a synchronous but irregular temporal pattern. There are different pieces of evidence suggesting such an oceanographic control.

First, food resources apparently vary from being very abundant (Santos) to limiting (São Sebastião). In $\mathrm{SR}$, phytoplankton standing stock is always very high due to urban pollution (Braga et al. 2000, Aguiar \& Braga 2007) and is often an order of magnitude higher than at SSC. This may explain why larval release numbers change in a similar way between these 2 localities (Fig. 4). Those differences in reproductive output are likely to be consistent through time, because sampling at São Sebastião in 20082009 and 2011 (Figs. 4 \& 7) provided very similar numbers, in both cases much lower than those observed in Santos by Bueno et al. (2010, Fig. 4). Apparently, restrictive food supply lies somewhere between the eutrophic conditions in Santos, where larval release was unaffected by the density of Skeletonema cells, and the southern SSC, where phytoplankton standing stock variation spiked around mesotrophic conditions and was positively correlated to naupliar release rate. Similarly, variation in food supply may determine whether reproduction is continuous or seasonal in tropical populations of Chthamalus malayensis separated by as little as only $200 \mathrm{~km}$ (Koh et al. 2005). Because chl a concentration 
lagged $6 \mathrm{~d}$ ahead, the most likely explanation is that this is the average time for food-deprived barnacles to build up gonad tissue. Turbulence and immersion apparently were not limiting larval release rate because the correction for chl a flow rendered a nonsignificant relationship. Our results do not provide support for the alternative hypothesis that phytoplankton cells signal favorable pelagic conditions and trigger naupliar hatching (e.g. Himmelman 1975, Starr et al. 1990), because release in this scenario should immediately follow microalgal blooming.

Second, larval release entrainment by tidal cycles is likely more efficient along the sampled coastline in SR than within the SSC. The southeastern Brazilian coast is exposed to a microtidal regime that hardly exceeds $1.5 \mathrm{~m}$ during spring tides and, therefore, the contribution of wind forcing and coastal circulation to sea level variation can be very important, particularly in straits and channels. In such semi-enclosed areas, high-frequency sea level anomalies driven by local wind stress and low-frequency anomalies caused by both wind forcing and incident coastal-trapped waves (Middleton \& Viera 1991) are common. Both processes may cause substantial sea level anomalies within the SSC, as suggested by the irregular flow over the rocks, which clearly departed from the expected fortnightly trend with maxima around spring tides. Thus, compared to barnacle populations in open coastlines, the oceanographic setup in the SSC seems less favorable for tidal entrainment.

\section{Disruption by temperature variation}

Thermal stress is often the cause of mass mortality events in both sessile and sedentary invertebrates in the rocky intertidal zone (Lewis 1954, Chan et al. 2006, Harley 2008). Even barnacles adapted to uppershore conditions are occasionally exposed to thermal stress beyond their tolerance. In spite of morphological and behavioral adaptations to greatly reduce water loss, body temperature at low tide on hot sunny days is usually higher (up to 15\%; Chan et al. 2006), not lower, than the rock surface (Hardin 1968, Helmuth \& Hofmann 2001, Chan et al. 2006). At SSC, peak extreme temperatures preceding major larval release events reached $36^{\circ} \mathrm{C}$ or more, which would translate to body temperatures higher than $40^{\circ} \mathrm{C}$ and exceed the thermal tolerance threshold even for higher-shore barnacles (Foster 1987). During these hot events, barnacles are under high mortality risk, and release of stored larvae may be viewed as a means to ensure surplus reproductive output.
Optimal resource allocation to reproduction depends on the rate of change of the residual reproductive value, that is, the amount of viable offspring to be produced after a given age (Williams 1966). Our results are in accordance with the terminal investment hypothesis (Clutton-Brock 1984), which states that all resources should be driven to current progeny when expectation for future reproduction is null. In Chthamalus bisinuatus, a nearly immediate response (1 d) would not involve energy transfer to ovaries but rather an intense eicosanoid synthesis that mediates egg hatching in barnacles (Clare 1997).

Acknowledgements. We thank M. Marques, who provided useful suggestions in an early stage of this study, and L. Menna-Barreto, R. Lopes, and 3 anonymous reviewers for carefully reading this manuscript and providing important criticism on which we based substantial redrafting. Many professional technicians and laboratory associates did not stint their efforts in helping us in the lab, especially E. da Silva, J. Sebroeck, J. Oliveira, E. Honuma, A. C. Mazzuco, L. Gladek, M. Ito, P. Guerra, and R. Duarte. For them, our sincere 'thank you'. Financial support was provided by the Fundação de Amparo à Pesquisa do Estado de São Paulo (FAPESP) as a MSc grant to P.K. (\#2009/12645-0) and through a research grant to A.A.V.F. (\#2008/10085-5). This is a contribution of the Research Centre for Marine Biodiversity of the University of São Paulo (NP-Biomar/USP).

\section{LITERATURE}

Aguiar VMC, Braga ES (2007) Seasonal and tidal variability of phosphorus along a salinity gradient in the heavily polluted estuarine system of Santos/São Vicente-São Paulo, Brazil. Mar Pollut Bull 54:464-471

Aidar E, Gaeta SA, Gianesella-Galvão SMF, Kutner MBB, Teixeira C (1993) Ecossistema costeiro subtropical: nutrientes dissolvidos, fitoplâncton e clorofila-a e suas relações com as condições oceanográficas na região de Ubatuba, SP. Publ Esp Inst Oceanogr, S Paulo 10:9-43

Arar EJ, Collins GB (1997) In vitro determination of chlorophyll $a$ and pheophytin $a$ in a marine and freshwater algae by fluorescence. National Exposure Research Laboratory, Office of Research and Development, US Environmental Protection Agency, Cincinnati, OH

Bernier NB, Thompson KR (2007) Tide-surge interaction off the east coast of Canada and northeastern United States. J Geophys Res 112:C06008, doi:10.1029/2006JC003739

Bolt SRL, Reid DG, Naylor E (1989) Effects of combined temperature and salinity on the entrainment of endogenous rhythms in the shore crab Carcinus maenas. Mar Behav Physiol 14:245-254

Braga ES, Bonetti CVDH, Burone L, Bonetti J (2000) Eutrophication and bacterial pollution caused by industrial and domestic wastes at the Baixada Santista estuarine system - Brazil. Mar Pollut Bull 40:165-173

> Bueno M, Flores AAV (2008) A sampling device to quantify offspring release of sessile marine invertebrates. Invertebr Reprod Dev 52:41-44 
Bueno M, Moser GAO, Tocci BRC, Flores AAV (2010) Retention-favorable timing of propagule release in barnacles and periwinkles. Mar Ecol Prog Ser 414:155-165

Burrows MT, Hawkins SJ, Southward AJ (1992) A comparison of reproduction in co-occurring chthamalid barnacles, Chthamalus stellatus (Poli) and Chthamalus montagui Southward. J Exp Mar Biol Ecol 160:229-249

- Caspers H (1984) Spawning periodicity and habitat of the palolo worm Eunice viridis (Polychaeta: Eunicidae) in the Samoan Islands. Mar Biol 79:229-236

Chan BKK, Morritt D, De Pirro M, Leung KMY, Williams GA (2006) Summer mortality: effects on the distribution and abundance of the acorn barnacle Tetraclita japonica on tropical shores. Mar Ecol Prog Ser 328:195-204

Chatfield C (1989) The analysis of time series: an introduction, 6th edn. Chapman \& Hall, New York, NY

$>$ Chatterton TD, Williams BG (1994) Activity patterns of the New Zealand cancrid crab Cancer novazelandiae (Jacquinot) in the field and laboratory. J Exp Mar Biol Ecol 178:261-274

> Clare AS (1997) Eicosanoids and egg-hatching synchrony in barnacles: evidence against a dietary precursor to egghatching pheromone. J Chem Ecol 23:2299-2312

Cloern JE (1996) Phytoplankton bloom dynamics in coastal ecosystems: a review with some general lessons from sustained investigation of San Francisco Bay, California. Rev Geophys 34:127-168

> Clutton-Brock TH (1984) Reproductive effort and terminal investment in iteroparous animals. Am Nat 123:212-229

> Crisp DJ, Patel B (1969) Environmental control of the breeding of three boreo-arctic cirripedes. Mar Biol 2:283-295

> Deruyck AMC, McLachlan A, Donn TE (1991) The activity of three intertidal sand beach isopods (Flabellifera, Cirolanidae). J Exp Mar Biol Ecol 146:163-180

Eston VR, Galves A, Jacobi CM, Langevin R, Tanaka NI (1986) Chthamalus bisinuatus (Cirripedia) and Brachidontes solisianus (Bivalvia) spatial interactions: a stochastic model. Ecol Model 34:99-113

Evans WG (1976) Circadian and circatidal locomotory rhythms in the intertidal beetle Thalassotrechus barbarae (Horn): Carabidae. J Exp Mar Biol Ecol 22:79-90

Forward RB (1987) Larval release rhythms of decapod crustaceans: an overview. Bull Mar Sci 41:165-176

Foster BA (1987) Barnacle ecology and adaptation. In: Southward AJ (ed) Barnacle biology. Balkema, Rotterdam, p 113-133

Foster BA, Nott JA (1969) Sensory structures in the opercula of the barnacle Elminius modestus. Mar Biol 4:340-344

Franke HD (1986) The role of light and endogenous factors in the timing of the reproductive cycle of Typosillis prolifera and some other polychaetes. Am Zool 26:433-445

Hardin DD (1968) A comparative study of lethal temperatures in the limpets Acmaea scabra and Acmaea digiralis. Veliger 11:83-87

- Harley CDG (2008) Tidal dynamics, topographic orientation, and temperature-mediated mass mortalities on rocky shores. Mar Ecol Prog Ser 371:37-46

> Harris GP (1980) Temporal and spatial scales in phytoplankton ecology. Mechanisms, methods, models and management. Can J Fish Aquat Sci 37:877-900

> Harrison PL, Babcock RC, Bull GD, Oliver JK, Wallace CC, Willis BL (1984) Mass spawning in tropical reef corals. Science 223:1186-1189

> Helmuth BST, Hofmann GE (2001) Microhabitats, thermal heterogeneity, and patterns of physiological stress in the rocky intertidal zone. Biol Bull (Woods Hole) 201: 374-384

> Himmelman JH (1975) Phytoplankton as a stimulus for spawning in three marine invertebrates. J Exp Mar Biol Ecol 20:199-214

Hines AH (1978) Reproduction in three species of intertidal barnacles from central California. Biol Bull (Woods Hole) 154:262-281

Javoiš J, Tammaru T (2004) Reproductive decisions are sensitive to cues of life expectancy: the case of a moth. Anim Behav 68:249-255

Karlson P, Luscher M (1959) 'Pheromones': a new term for a class of biologically active substances. Nature 183: $55-56$

Koh LL, O'Riordan RM, Lee WJ (2005) Sex in the tropics: reproduction of Chthamalus malayensis Pilsbury (class Cirripedia) at the equator. Mar Biol 147:121-133

Korringa P (1947) Relations between the moon and periodicity in the breeding of marine animals. Ecol Monogr 17: 347-381

Lalli CM, Parsons TR (1997) Biological oceanography: an introduction. Butterworth-Heinemann, Oxford

- Le Bouteiller A, Blanchot J, Rodier M (1992) Size distribution patterns of phytoplankton in the western Pacific: towards a generalization for the tropical ocean. Deep Sea Res A 39:805-823

> Lewis JR (1954) Observations on a high-level population of limpets. J Anim Ecol 23:85-100

Lewis JR (1964) The ecology of rocky shores. English Universities Press, London

Mackas DL, Denman KL, Abbott MR (1985) Plankton patchiness: biology in the physical vernacular. Bull Mar Sci 37: 652-674

Middleton JF (1991) Coastal-trapped wave scattering into and out of straits and bays. J Phys Oceanogr 21:681-694

Middleton JF, Viera F (1991) The forcing of low frequency motions within Bass Strait. J Phys Oceanogr 21:695-708

Morgan SG (1995) The timing of larval release. In: McEdward L (ed) Ecology of marine invertebrate larvae. CRC Press, Boca Raton, FL, p 157-191

- Morgan SG, Christy JH (1994) Plasticity, constraint, and optimality in reproductive timing. Ecology 75:2185-2203

> Neumann D (1978) Entrainment of a semilunar rhythm by simulated tidal cycles of mechanical disturbance. J Exp Mar Biol Ecol 35:73-85

- Neumann D (1989) Circadian components of semilunar and lunar timing mechanisms. J Biol Rhythms 4:173-182

Newell RC (1970) Biology of intertidal animals. American Elsevier Publishing, New York, NY

Palmer JD (1995) The biological rhythms and clocks of intertidal animals. Oxford University Press, New York, NY

Pyper BJ, Peterman RM (1998) Comparison of methods to account for autocorrelation in correlation analyses of fish data. Can J Fish Aquat Sci 55:2127-2140

Rayner JN (1971) An introduction to spectral analysis. Pion Press, London

> Roitberg BD, Sircom J, Roitberg CA, van Alphen JJM, Mangel M (1993) Life expectancy and reproduction. Nature 364:108

> Saigusa M (1980) Entrainment of a semilunar rhythm by simulated moonlight cycle in the terrestrial crab, Sesarma haematocheir. Oecologia 46:38-44

> Shoaf WT, Lium BW (1976) Improved extraction of chlorophyll $a$ and $b$ from algae using dimethyl sulfoxide. Limnol Oceanogr 21:926-928 
Sokal R, Rohlf FJ (1995) Biometry: the principles and practice of statistics in biological research, 3rd edn. WH Freeman \& Company, New York, NY

Southward AJ, Crisp DJ (1965) Activity rhythms of barnacles in relation to respiration and feeding. $\mathrm{J}$ Mar Biol Assoc UK 45:161-185

Starr M, Himmelman JH, Therriault JC (1990) Direct coupling of marine invertebrate spawning with phytoplankton blooms. Science 247:1071-1074

Strutton PG, Mitchell JG, Parslow JS, Greene RM (1997) Phytoplankton patchiness: quantifying the biological contribution using fast repetition rate fluorometry. J Plankton Res 19:1265-1274

Switzer AC, Kamykowski D, Zentara SJ (2003) Mapping nitrate in the global ocean using remotely sensed sea surface temperature. J Geophys Res 108(C8):3280, doi: 10.1029/2000JC000444

Tanaka MO, Duarte LFL (1998) Recruitment variation of the barnacle Chthamalus bisinuatus Pilsbry 1916 in an exposed rocky shore in southeast Brazil. Bull Mar Sci 62: 285-292

Underwood AJ (1997) Experiments in ecology: their logical

Editorial responsibility: Pei-Yuan Qian,

Kowloon, Hong Kong SAR design and interpretation using analysis of variance. Cambridge University Press, Cambridge

Walley LJ (1969) Studies on the larval structure and metamorphosis of Balanus balanoides (L.). Philos Trans R Soc Lond B 256:237-280

Weinbauer MG, Fuks D, Peduzzi P (1993) Distribution of viruses and dissolved DNA along a coastal trophic gradient in the northern Adriatic Sea. Appl Environ Microbiol 59:4074-4082

Williams GC (1966) Natural selection, the costs of reproduction, and a refinement of Lack's principle. Am Nat 100: 687-690

Williams BG, Naylor E (1969) Synchronization of the locomotor tidal rhythm of Carcinus. J Exp Mar Biol Ecol 51: 715-725

Williams BG, Naylor E, Chatterton TD (1985) The activity patterns of New Zealand mud crabs under field and laboratory conditions. J Exp Mar Biol Ecol 89:269-282

Yannicelli B, Palacios R, Gimenez L (2001) Activity rhythms of two cirolanid isopods from an exposed microtidal sandy beach in Uruguay. Mar Biol 138: 187-197

Submitted: February 29, 2012; Accepted: August 14, 2012 Proofs received from author(s): December 6, 2012 